\title{
Reinforcement Coating on Stainless Steel and Copper Powders
}

\author{
J. M. Castanho*, M. Matos and M. T. Vieira
}

* ICEMS-Materials and Surface Engineering Group, Mechanical Engineering Department, Polo II, University of Coimbra, Coimbra, Portugal

jose.castanho@dem.uc.pt

The continuous miniaturization of the mechanical components and devices push to microfabrication techniques such as $\mu$ PIM (micro-Powder Injection Moulding) and laser sintering, particularly DMLS (Direct Metal Laser Sintering) [1].

To achieve such proposes novel feedstocks involving metal powders with enhanced surfaces properties are required. The conventional powders production, gas and water atomization does not fulfil these surface properties. In order to produce particles with a higher surface-to-volume ratio, the surface morphology of the particles must be modified. The powders' surface can be tailored by the presence of a thin film. Moreover, magnetic and sintering properties can be adapted with convenient thin films of different metals.

Micrometric commercial copper (99\% purity) and austenitic stainless steel 316L powders with two different shapes: irregular and spherical were used as the starting material. These powders were coated in a modified home sputtering device. Stainless steel (SS) 304L and copper nanostructured thin films were deposited on copper and on SS 316L powders, respectively. The coating procedure were tailored to enhance the magnetic properties of the copper powders [2], and to extend the liquid phase sintering, improving the performance of the sintered parts of SS 316L powders [3].

The coated and uncoated powders have been subjected to microstructural studies by environmental scanning electron microscope (SEM) coupled with energy dispersive spectroscopy (EDS) and backscattered electron (BSE) and for the coated ones were made Electron Probe Micro Analysis (EPMA).

The deposition method is able to coat homogeneously the powders' surface, as can be observed by the SEM image with a backscattered electron (BSE) detector (figure 1).

\section{Experimental details}

Micrometric commercial copper (99\% purity) and austenitic stainless steel 316L powders with two different shapes: irregular and spherical were used as the starting material. The powders were coated using a homemade dc magnetron sputtering system with a vacuum chamber equipped with a powder vibration system and a continuous powder feed system. Copper or stainless steel 304L (AISI) targets were used in order to coat the stainless steel or copper powders, respectively. The deposition parameters were constant in all depositions and were as follows: the deposition pressure of argon (99.999) was $5 \times 10^{-1} \mathrm{~Pa}$, after a previous chamber evacuation down to $10^{-4} \mathrm{~Pa}$, and the density discharge power was $16.7 \mathrm{~kW} / \mathrm{m}^{2}$.

In order to determine the morphology and topography of the surfaces, the samples were observed by scanning electron microscopy (SEM) Philips - XL30 coupled with backscattered electron image system. The elemental distribution of the copper and iron on the coated powders were evaluated by using an electron probe microanalysis (EPMA) Cameca SX50.

\section{Results and Discussion}


The modified sputtering system proves to be able to perfectly coat the powder's surface as can be clearly confirmed by the backscattered electron image of the copper powders coated by SS (figure 1) and by the $\mathrm{Cu}$ and $\mathrm{Fe}$ elemental distribution evaluated by electron probe microanalysis (EPMA) (figure 2). In spite of a very few small uncoated particles (brighter) the copper particles are statistically perfectly deposited (figure 1).

The iron distribution mapping shows also the perfect coating process (blue) of the copper powders, but the low thickness of the stainless steel films is not enough to mask the copper signal and the elemental distribution still show the copper particles (figure 2). This fact, confirms the above statement saying the perfect deposition of the powders.

The columnar growth of the thin is replicated on the powders spherical or irregular surface. This columnar growth induces a significant increase in the powder's surface roughness (figure 3). In fact, the powders' surface is totally coated and the peculiar topography of the coated surface is much rougher than the uncoated powders. The increase of roughness on the powders' surface increases their specific surface area.

The flowability of the powders is a property that is closely related with the surface characteristics involving the shape, the structure and the topography. The presence of a stainless steel and copper thin films on copper and stainless steel powders' surface, respectively, increases the flowability relatively to the uncoated ones. Thus, the topography and the specific surface area play the major role on this powder property.

However, the sputtered thin films present a nanocrystalline structure, which also decreases of the inter-particle friction.

\section{Concluding remarks}

A modified sputtering system proves to be able to coat uniformly powders' surface. Novel feedstocks can be developed with tailored surface properties. Thus, copper powders with enhanced ferromagnetic properties and SS 316L powders with enhanced liquid phase sintering can be manufactured.

\section{References}

[1] J.M. Castanho, M.T. Vieira, M. Matos, B. Trindade, Journal of Alloys and Compounds 434-435 (2007) 383-385.

[2] M. V. Cleemput, H. Jones, M. Burgt, IEEE Transactions on Magnetics, Vol.32, No.4 (1996) 2466-2469.

[3] W. Grunberger, M. Heilmaier, L. Schultz, Materials Letters, 52 (2002) 154-158. 


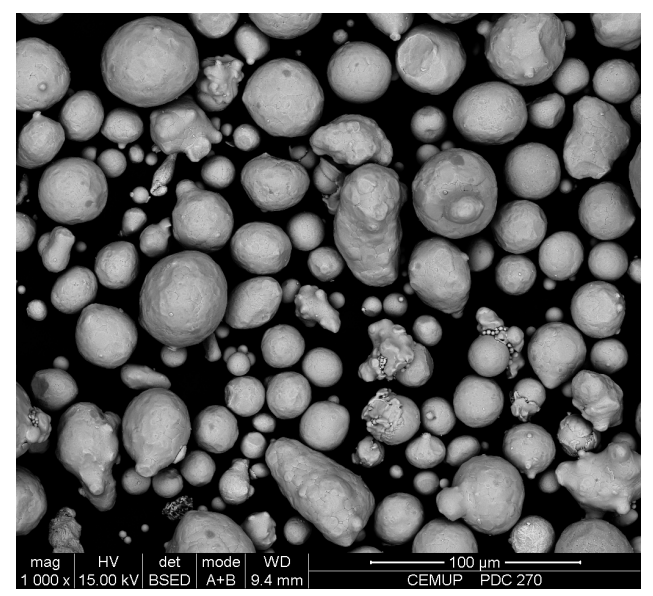

Figure 1 - Backscattered electron image of Cu powders coated with SS 304L.

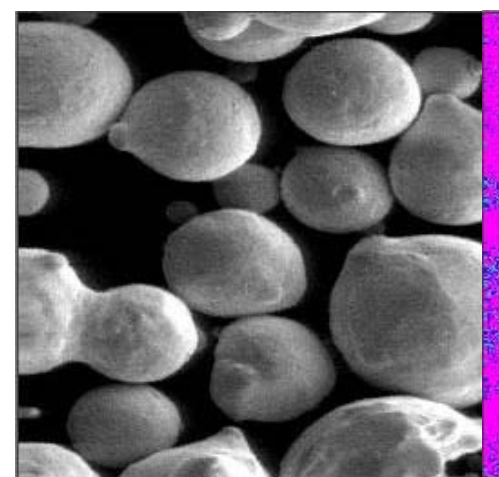

a)

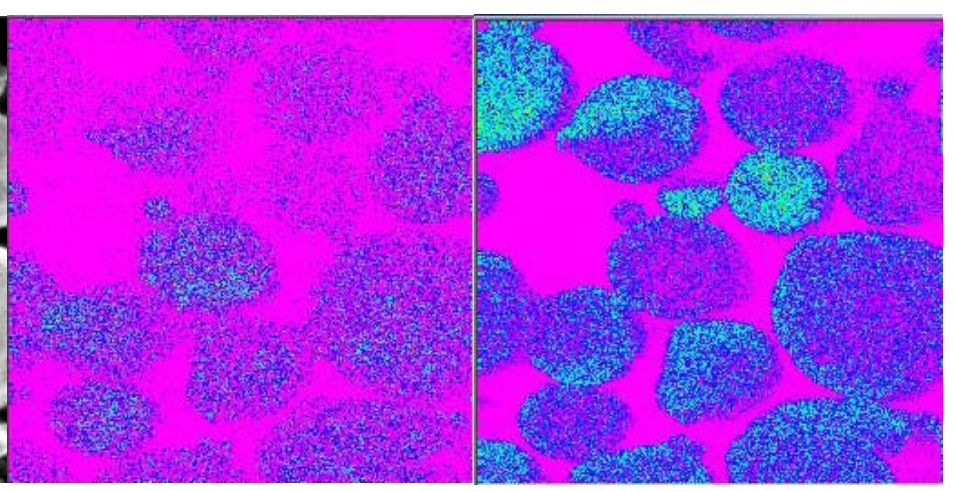

b)

c)

Figure 2 - SEM image of Cu powders coated with SS 304L, a) secondary electrons, b) copper elemental distribution and c) iron elemental distribution. 


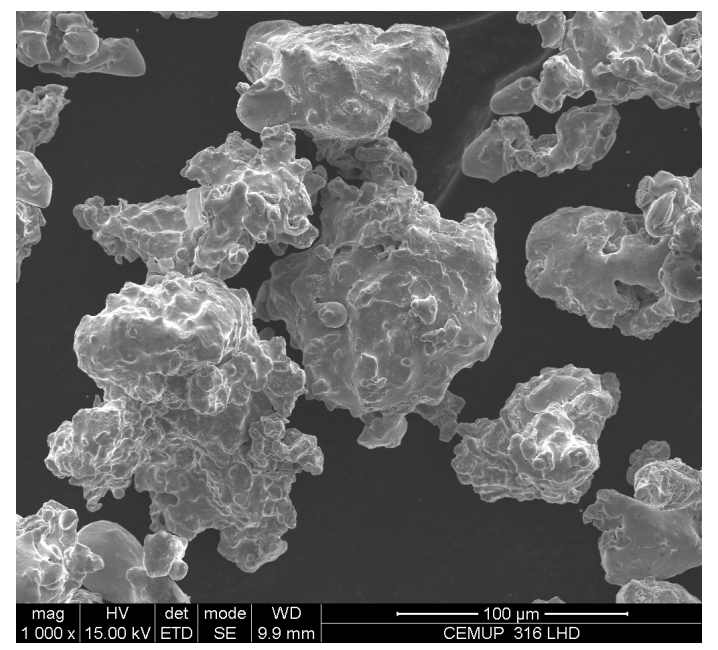

a)

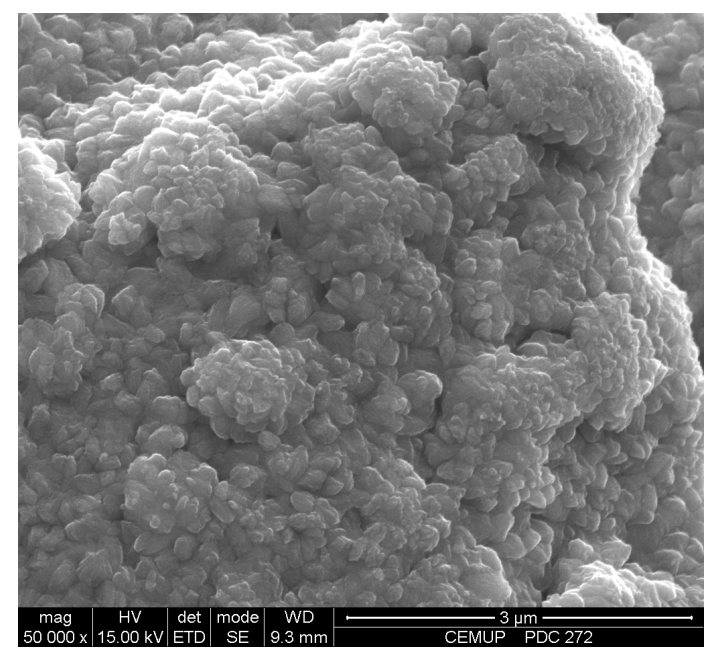

b)

Figure 3 - Irregular-shaped stainless steel 316LHD powders (a) uncoated and (b) coated with copper. 